\title{
INVESTIGATION OF MULTICOMPONENT LEAD-FREE SOLDERS
}

\begin{abstract}
According to the directives (RoHS and WEEE) adopted by the European Union, lead has been banned from the manufacturing processes because of its health and environmental hazards. Therefore, the development of lead-free solders is one of the most important research areas of the electronic industry. This paper investigates multicomponent $\mathrm{Sn}-\mathrm{Ag}$-Cu based lead-free solders with different compositions. The properties of the six-component Innolot ( $\mathrm{SAC}+\mathrm{BiSbNi}$ ) and two low-Ag containing alloys were compared with the widespread used SAC307 solder. Microstructure investigations and X-ray diffraction measurements were performed to analyze and identify the formed phases, furthermore, tensile tests and microhardness measurements were executed to determine the mechanical properties of the examined solders.

Keywords: lead-free solder, multicomponent, microstructure, X-ray diffraction, mechanical properties
\end{abstract}

\section{Introduction}

The environmental impact of solder alloys is an important factor during manufacturing. Because of environmental reasons, the European Union issued the WEEE = Waste Electrical and Electronic Equipment and RoHS = Restriction of Hazardous Substances directives. These limit the use of certain hazardous substances, such as lead in electronic components. Therefore, the electronic industry has to switch to lead-free solder alloys from the conventional $\mathrm{Sn}-\mathrm{Pb}$ alloys $[1,2]$.

The $\mathrm{Sn}-\mathrm{Ag}-\mathrm{Cu}(\mathrm{SAC})$ alloys are the most commonly used lead-free solders. However, the available alloys cannot replace the well-proven $\mathrm{Pb}$-containing alloys without difficulties which motivates the development of novel alloy types [3,4]. Our research focuses on the examination of a widely used solder alloy SAC307, a novel, 6-component alloy named Innolot (marked as "SAC307+BiSbNi ") and two not yet widely used solder alloys with decreased Ag content.

TABLE 1

Chemical composition of the solder alloys determined by ICP $[$ wt.\%]

\begin{tabular}{|c|c|c|c|c|c|c|}
\hline \hline Solder & Ag & $\mathbf{C u}$ & $\mathbf{B i}$ & $\mathbf{S b}$ & $\mathbf{N i}$ & Sn \\
\hline SAC307 & 3.03 & 0.76 & 0.005 & 0.008 & 0.002 & bal. \\
\hline SAC307+BiSbNi & 3.08 & 0.76 & 2.98 & 1.36 & 0.12 & bal. \\
\hline SACX0807+Bi & 0.68 & 0.72 & 2.71 & 0.027 & 0.005 & bal. \\
\hline SACX+BiSbNi & 0.47 & 1.35 & 4.29 & 2.68 & 0.19 & bal. \\
\hline
\end{tabular}

The Innolot alloy (from now on SAC307+BiSbNi) is a modification of the widely used SAC307 alloy. As seen in Table 1 , more additives $-\mathrm{Bi}, \mathrm{Sb}$ and $\mathrm{Ni}$ - are added to the $\mathrm{SAC}$ system to improve the mechanical characteristics. Some part of $\mathrm{Bi}$ and $\mathrm{Sb}$ are in solution, while Ni improves strength by forming intermetallic compounds $[5,6]$.

Due to the high Ag content of SAC307 and SAC307+BiSbNi alloys, their production is expensive. Therefore, solder alloy manufacturers aim to develop alloys with less Ag content [7]. The last two alloys in Table 1 are good examples for such an effort, which contain 0.7 and 0.5 wt. $\% \mathrm{Ag}$.

The objectives of the performed examinations are the following. To compare the SAC307 alloy with SAC307+BiSbNi, and to investigate how does the decreased Ag content affect the mechanical and microstructural properties of the examined alloys.

\section{Experimental}

The bulk solder materials were produced by Henkel Hungary Ltd. The bulk alloys were put in a ceramic crucible and melted in an electric resistance furnace at $400^{\circ} \mathrm{C}$. After 15 minutes of isothermal holding, the melt was poured into a steel mould preheated to $200^{\circ} \mathrm{C}$. After solidification, the die was disassembled and the ingots were removed. 5 tensile test specimens were casted from each alloy, while one sample was casted for X-ray diffraction (XRD) examinations.

\footnotetext{
* INSTITUTE OF PHYSICAL METALLURGY, METAL FORMING AND NANOTECHNOLOGY, UNIVERSITY OF MISKOLC, H-3515 MISKOLC-EGYETEMVAROS, B1/109., HUNGARY ** MTA-ME MATERIALS SCIENCE RESEARCH GROUP, UNIVERSITY OF MISKOLC, H-3515 MISKOLC-EGYETEMVAROS, HUNGARY

\# Corresponding author: fembenke@uni-miskolc.hu
} 
Samples were cut from the $11 \mathrm{~mm}$ diameter cylinder ingots for microstructure examinations that were mounted in Duracryl type resin. After standard metallographic sample preparations (grinding: P240, P320, P500, P800, P1200, P2000, P2400 and polishing: MD Mol and MD clothes using Lubricant Blue and a final polishing with $0.02 \mu \mathrm{m} \mathrm{SiO}_{2}$ paste), microstructure examinations were carried out with a Zeiss AxioVision Imager m1M optical microscope and a Zeiss EVO MA10 scanning electron microscope (SEM), equipped with EDAX microprobe (EDX) [7]. An additional etching with $38 \% \mathrm{HF}$ for $30 \mathrm{~s}$ was applied for SEM examinations.

Phase analysis was performed with a Phillips PW1830 type diffractometer equipped with a diffracted beam monochromator operating with $\mathrm{CuK} \alpha$ radiation. Standard (DIN-EN-50125) tensile test specimens (Fig. 1) were machined from the ingots. An Instron 5982 type universal mechanical tester with $10 \mathrm{kN}$ maximal force was used for the mechanical tests. Experiments were carried out at room temperature with $3 \mathrm{~mm} /$ minute speed which equals $10^{-3} \mathrm{~s}^{-1}$ strain rate.

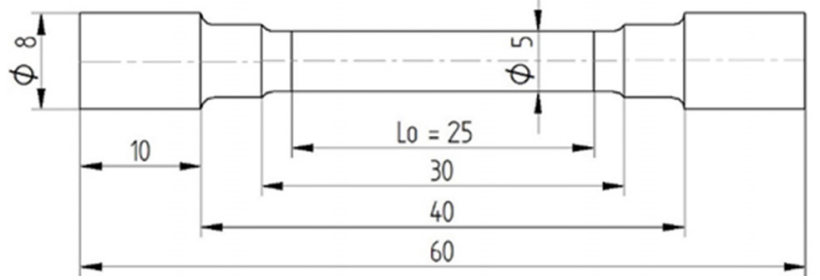

Fig. 1. The applied tensile test specimen

Vickers hardness was measured on the alloys with $0.3 \mathrm{~kg}$ load and $10 \mathrm{~s}$ indention time using an Instron Tukon $2100 \mathrm{~B}$ equipment. 10 parallel measurements were made for all alloy types.

\section{Results and discussion}

\subsection{Microstructure}

Fig. 2 shows the optical microscope images of the alloys. The SAC307, SAC307+BiSbNi and SACX0807+Bi alloys have hypoeutectic microstructures with $\beta$-Sn dendrites and different amount and types of eutectics. The SACX+BiSbNi alloy has hypereutectic structure consisting of primary $(\mathrm{Cu}, \mathrm{Ni})_{6} \mathrm{Sn}_{5}$ intermetallic compounds and different eutectics. This alloy clearly shows that this amount of $\mathrm{Cu}$ content increase and $\mathrm{Ag}$ content decrease cause dramatic changes in the microstructure. The large, coarse particles of primary $\left(\mathrm{Cu}, \mathrm{Ni}_{6} \mathrm{Sn}_{5}\right.$ phase degrade the mechanical properties of the solder alloy [7].

The SEM images and measured compositions of the alloys are shown in Fig. 3. It can be concluded that the SAC307 consist of $\beta$-Sn solid solution and fine eutectic containing $\mathrm{Ag}$ and $\mathrm{Cu}$. For the other three alloys, the Bi containing eutectic also appears due to the 3 and 4 wt.\% Bi content. Particles of the (Bi) solid solution are clearly visible on the SEM images as white particles owing to its high atomic number. The individual phases of the

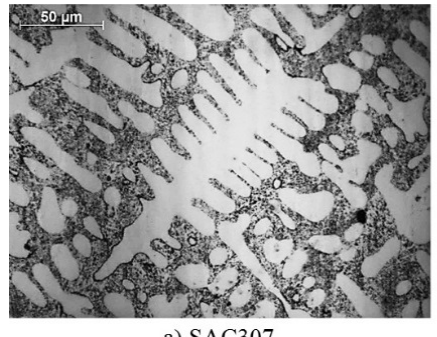

a) $\mathrm{SAC} 307$

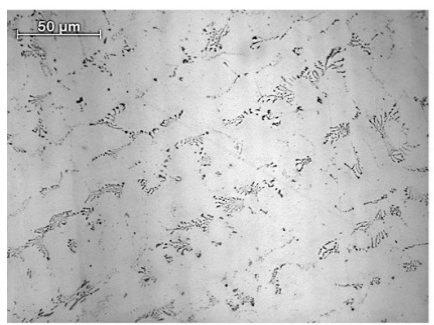

c) $\mathrm{SACX} 0807+\mathrm{Bi}$

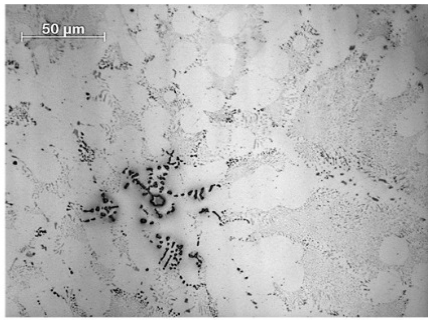

b) $\mathrm{SAC} 307+\mathrm{BiSbNi}$

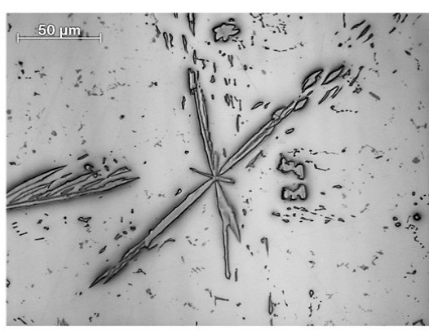

d) $\mathrm{SACX}+\mathrm{BiSbNi}$
Fig. 2. Optical microscopic images of the examined solder alloys

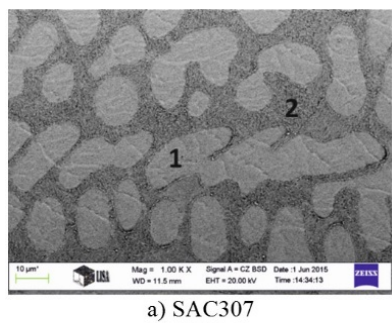

\begin{tabular}{|c|c|c|}
\hline \multirow{2}{*}{ Element } & \multicolumn{2}{|c|}{ Analysed phases } \\
\cline { 2 - 3 } & $\mathbf{1}$ & $\mathbf{2}$ \\
\cline { 2 - 3 } & $\boldsymbol{\beta}-\mathbf{S n}$ & $\begin{array}{c}(\boldsymbol{\beta}-\mathbf{S n}+ \\
\left.\mathbf{A g}_{3} \mathbf{S n}+\mathbf{C u}_{6} \mathbf{S n}_{5}\right)\end{array}$ \\
\hline $\mathbf{S n}$ & 99.50 & 87.85 \\
\hline $\mathbf{A g}$ & 0.50 & 7.48 \\
\hline $\mathbf{C u}$ & - & 4.67 \\
\hline
\end{tabular}

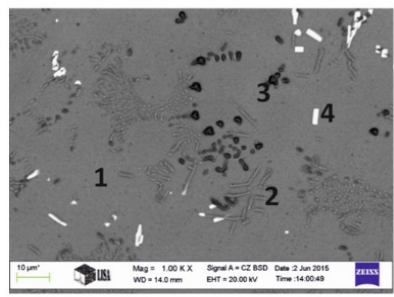

b) $\mathrm{SAC} 307+\mathrm{BiSbNi}$

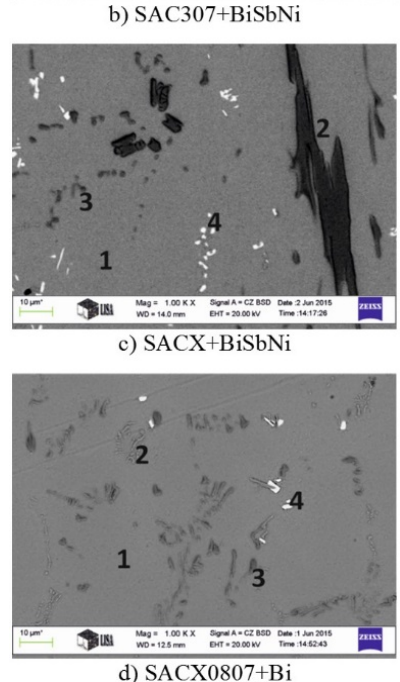

\begin{tabular}{|c|c|c|c|c|}
\hline \multirow{2}{*}{ Element } & \multicolumn{4}{|c|}{ Analysed phases } \\
\cline { 2 - 5 } & $\mathbf{1}$ & $\mathbf{2}$ & $\mathbf{3}$ & $\mathbf{4}$ \\
\cline { 2 - 5 } & $\boldsymbol{\beta}-\mathbf{S n}$ & $\mathbf{A g}_{3} \mathbf{S n}$ & $(\mathbf{C u}, \mathbf{N i})_{6} \mathbf{S n}_{\mathbf{5}}$ & $\mathbf{( B i})$ \\
\hline $\mathbf{S n}$ & 95.05 & 30.93 & 51.58 & 15.13 \\
\hline $\mathbf{A g}$ & 0.25 & 66.33 & - & - \\
\hline $\mathbf{C u}$ & - & 2.74 & 41.19 & - \\
\hline $\mathbf{B i}$ & 2.89 & - & - & 84.87 \\
\hline $\mathbf{S b}$ & 1.81 & - & - & - \\
\hline $\mathbf{N i}$ & - & - & 7.23 & - \\
\hline
\end{tabular}

\begin{tabular}{|c|c|c|c|c|}
\hline \multirow{2}{*}{ Element } & \multicolumn{4}{|c|}{ Analysed phases } \\
\cline { 2 - 5 } & $\mathbf{1}$ & $\mathbf{2}$ & $\mathbf{3}$ & $\mathbf{4}$ \\
\cline { 2 - 5 } & $\boldsymbol{\beta}-\mathbf{S n}$ & \multicolumn{2}{|c|}{$(\mathbf{C u}, \mathbf{N i}) 6 \mathbf{S n} \mathbf{5}$} & $\mathbf{( B i})$ \\
\hline $\mathbf{S n}$ & 94.25 & 46.78 & 61.89 & 46.00 \\
\hline $\mathbf{C u}$ & - & 45.41 & 36.03 & - \\
\hline $\mathbf{B i}$ & 2.76 & - & - & 54.00 \\
\hline $\mathbf{S b}$ & 2.99 & - & - & - \\
\hline $\mathbf{N i}$ & - & 7.81 & 2.08 & - \\
\hline
\end{tabular}

\begin{tabular}{|c|c|c|c|c|}
\hline \multirow{2}{*}{ Element } & \multicolumn{4}{|c|}{ Analysed phases } \\
\cline { 2 - 5 } & $\mathbf{1}$ & $\mathbf{2}$ & $\mathbf{3}$ & $\mathbf{4}$ \\
\cline { 2 - 5 } & $\boldsymbol{\beta}-\mathbf{S n}$ & $\mathbf{A g}_{3} \mathbf{S n}$ & $\mathbf{C u}_{6}$ Sn5 & $\mathbf{( B i )}$ \\
\hline $\mathbf{S n}$ & 96.09 & 49.35 & 71.17 & 34.02 \\
\hline $\mathbf{A g}$ & 0.65 & 50.65 & - & - \\
\hline $\mathbf{C u}$ & 1.12 & - & 28.83 & - \\
\hline $\mathbf{B i}$ & 2.14 & - & - & 65.98 \\
\hline
\end{tabular}

Fig. 3. SEM images of the examined alloys and measured compositions (EDS, at.\%) of the phases

eutectic are much better distinguishable on the SEM images, namely $\beta$-Sn solid solution and $\mathrm{Ag}_{3} \mathrm{Sn}$ and $(\mathrm{Cu}, \mathrm{Ni})_{6} \mathrm{Sn}_{5}$ phases. Due to the high amount of $\mathrm{Cu}$ and $\mathrm{Ni}$ content, large primary $(\mathrm{Cu}, \mathrm{Ni})_{6} \mathrm{Sn}_{5}$ particles appear in the $\mathrm{SACX}+\mathrm{BiSbNi}$ alloy. 
Fig. 4 shows the diffraction patterns of the examined alloys. The high intensity reflections correspond to the $\beta$-Sn phase, while those of the intermetallic compounds are marked. Reflections of the $\mathrm{Ag}_{3} \mathrm{Sn}$ phase appear at $35,38,40,52,69,75,76^{\circ}$; those of the $\mathrm{Cu}_{6} \mathrm{Sn}_{5}$ phase are found at 43 and $60^{\circ}$ and those of the $\mathrm{Bi}$ phase are at 28 and $38^{\circ}$. The $\mathrm{Ag}_{3} \mathrm{Sn}$ and $\mathrm{Cu}_{6} \mathrm{Sn}_{5}$ phases were identified in all alloys, while $(\mathrm{Cu}, \mathrm{Ni})_{6} \mathrm{Sn}_{5}$ was found in the high $\mathrm{Ni}$ content alloy. The $\mathrm{Ag}_{3} \mathrm{Sn}$ phase has higher intensity in the SAC307 and the SAC307+BiSbNi alloy, while those are smaller for the $\mathrm{SACX}+\mathrm{BiSbNi}$ and $\mathrm{SACX} 0807+\mathrm{Bi}$ alloys. The intensities of the $\mathrm{Cu}_{6} \mathrm{Sn}_{5}$ reflections are similar for all four alloys. The $\mathrm{Bi}$ phase is present in all alloys except the SAC307. Similar intensities can be seen in the SAC307 and SAC307+BiSbNi alloys. The composition of SACX+BiSbNi alloy strongly differs from the previous ones, which is also visible on the XRD pattern as smaller intermetallic phase reflections and stronger Bi reflections. The pattern of the SACX+BiSbNi and the SACX0807+Bi alloys are similar.

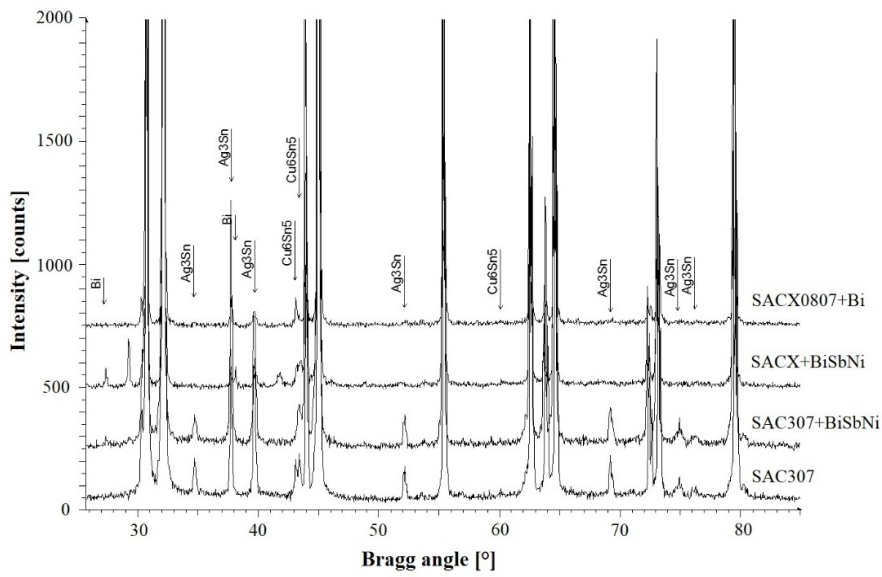

Fig. 4. XRD patterns of the examined alloys

\subsection{Mechanical properties}

Table 2. contains the results of tensile tests and hardness measurements. Figs. 5-8 show the yield strength (YS), ultimate tensile strength (UTS), elongation and Vickers hardness (HV) values. The UTS, 0.2 YS and HV0.3 of SAC $307+\mathrm{BiSbNi}$ is about twice as large, and the elongation is around half as those of SAC307 due to the alloying elements. The UTS and YS of the low Ag alloys are between those of SAC307 and a SAC307+BiSbNi. From those, hypoeutectic SACX0807+Bi has lower UTS and YS and higher elongation compared to hypereutectic $\mathrm{SACX}+\mathrm{BiSbNi}$. SACX+BiSbNi has the smallest elongation from the examined alloys (Fig. 7). Fig. 9 shows one typical stress-strain curves of the alloys. The negative effect of lowered Ag content on the mechanical properties can be observed. The hardness values of the lowered Ag content alloys are similar to those of SAC307+BiSbNi alloy, which is not in agreement with the UTS and YS variation.
Mechanical properties of the examined alloys

\begin{tabular}{|c|c|c|c|c|}
\hline \hline Solder & $\begin{array}{c}\text { 0.2YS } \\
\text { [MPa] }\end{array}$ & $\begin{array}{c}\text { UTS } \\
\text { [MPa] }\end{array}$ & $\begin{array}{c}\text { Elongation } \\
{[\text { \% ] }}\end{array}$ & HV0.3 \\
\hline SAC307 & $46.54 \pm 1.29$ & $39.03 \pm 1.47$ & $35.59 \pm 4.79$ & $15.7 \pm 0.5$ \\
\hline $\begin{array}{c}\text { SAC307 } \\
+\mathrm{BiSbNi}\end{array}$ & $88.68 \pm 3.82$ & $62.72 \pm 1.76$ & $17.09 \pm 2.61$ & $31.4 \pm 0.7$ \\
\hline SAC0807+Bi & $65.07 \pm 0.64$ & $44.34 \pm 0.95$ & $12.50 \pm 2.42$ & $30.0 \pm 2.1$ \\
\hline $\begin{array}{c}\text { SACX } \\
+\mathrm{BiSbNi}\end{array}$ & $75.62 \pm 4.48$ & $52.26 \pm 1.05$ & $7.48 \pm 2.64$ & $32.2 \pm 0.7$ \\
\hline
\end{tabular}

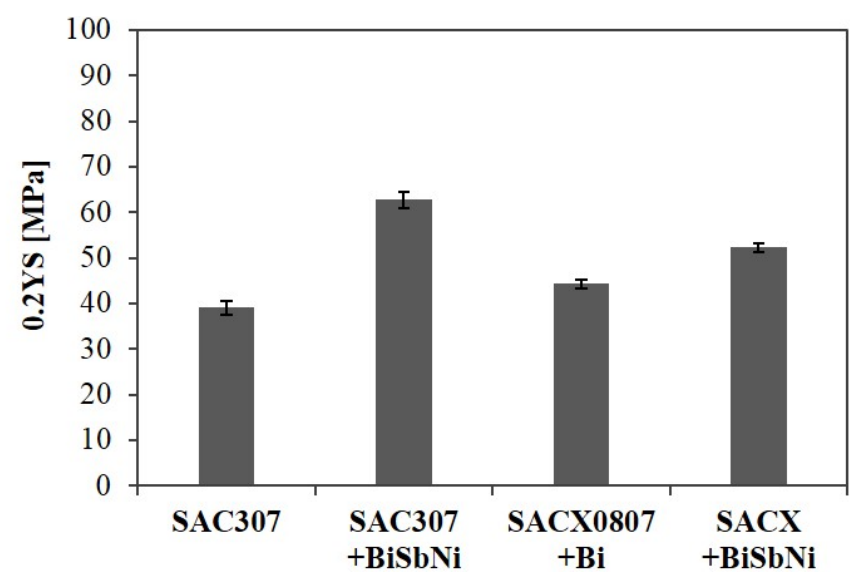

Fig. 5. Yield strength of the examined alloys

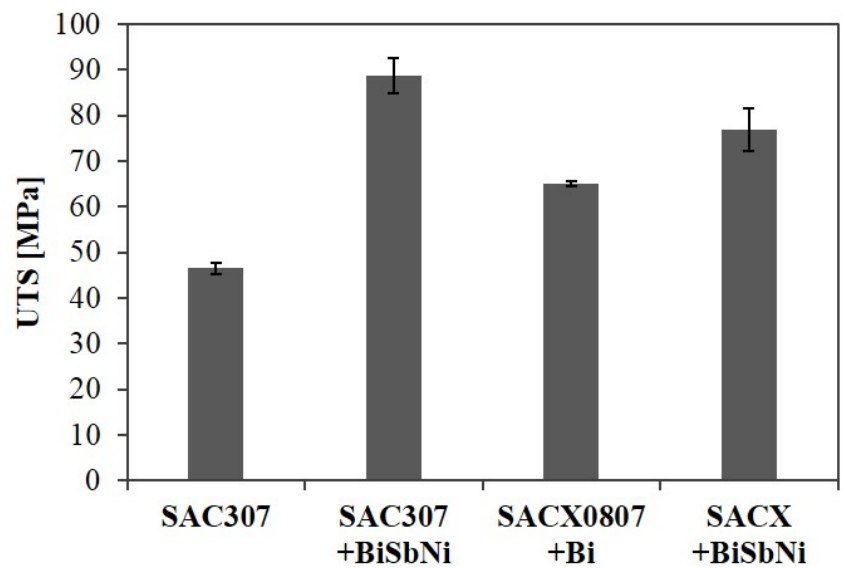

Fig. 6. Ultimate tensile strength of the examined alloys

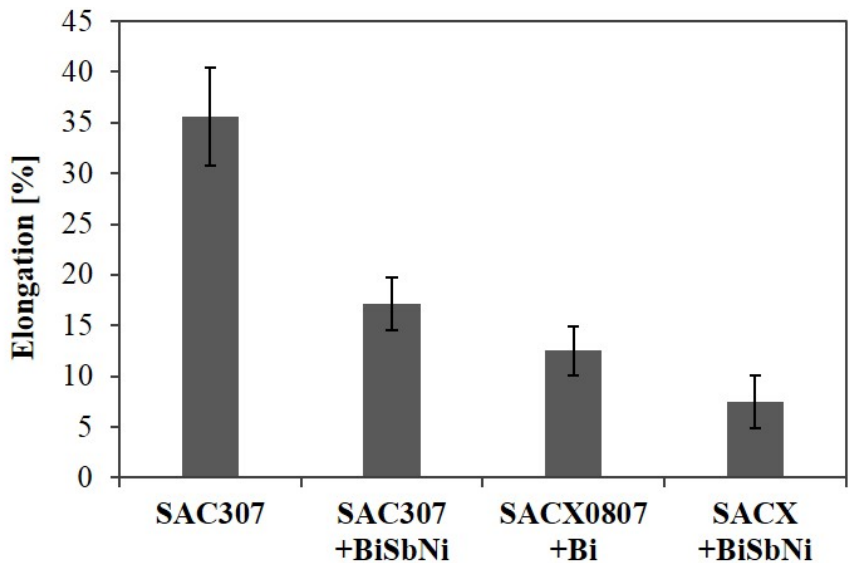

Fig. 7. Elongation of the examined alloys 


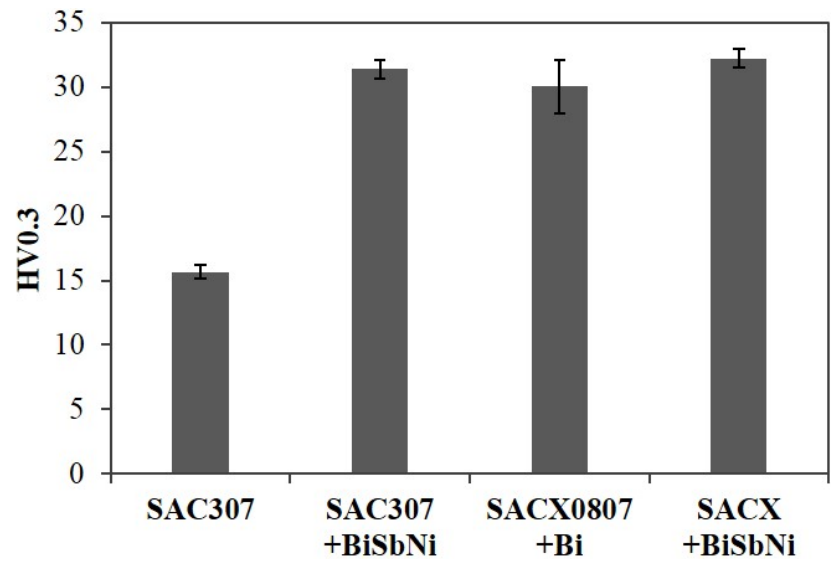

Fig. 8. Hardness of the examined alloys

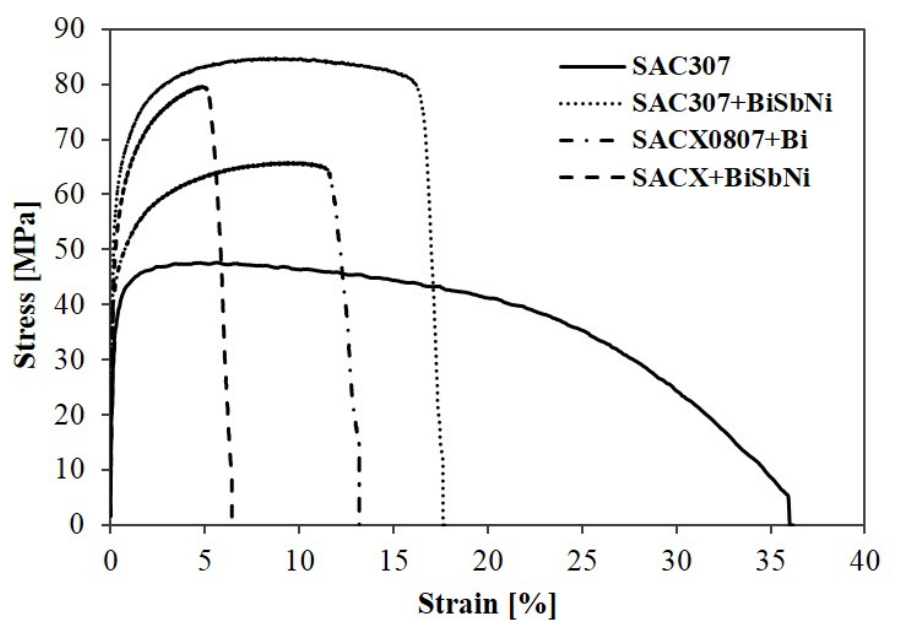

Fig. 9. Typical stress-strain curves of the examined alloys

\section{Conclusions}

The microstructural and mechanical properties of multicomponent, lead-free $\mathrm{Sn}-\mathrm{Ag}$-Cu based solder alloys were investigated. The following conclusions were deduced:

1. Due to the higher Ag content, larger amount of intermetallic compounds were formed in the SAC307 and SAC307+BiSbNi alloys. The Bi is present in the form of solid solution of the eutectic in the examined Bi-containing alloys. $(\mathrm{Cu}, \mathrm{Ni})_{6} \mathrm{Sn}_{5}$ intermetallic compounds are also present as primary phases in the SACX+BiSbNi alloy.

2. The ultimate tensile strength, yield strength and hardness of the SAC307+BiSbNi alloy are around twice as those of SAC307, and its elongation is about half of that of SAC307.
The ultimate tensile strength values of $\mathrm{SACX}+\mathrm{BiSbNi}$ and SACX0807+Bi alloys are in between those of SAC307 and $\mathrm{SAC} 307+\mathrm{BiSbNi}$, and $\mathrm{SACX}+\mathrm{BiSbNi}$ has the lowest elongation. These differences are due to the strength increasing effect of the intermetallic compounds and Bi which was revealed by the microstructure examinations.

Finally, if higher strength is required, SAC307+BiSbNi (Innolot) performs the best from the examined alloys, on the other hand, if higher elongation is desired, SAC307 performs the best. If cost efficiency is of major importance, SACX0807+Bi could be the best choice.

\section{Acknowledgments}

The authors would like to thank Dr. Olivér Bánhidi for the ICP measurements, Dr. Mária Svéda Kissné and Dr. Anna Sycheva for the SEM examinations, Dr. Tamás Mikó for the tensile tests. This research was carried out in the framework of the Center of Applied Materials Science and Nano-Technology at the University of Miskolc and it was supported by the ERNYO_13-1-2013-0007 project.

The research work performed by dr. Erzsébet Nagy was supported by the European Union and the State of Hungary, co-financed by the European Social Fund in the framework of TÁMOP-4.2.4.A/2-11-1-2012-0001 'National Excellence Program'.

\section{REFERENCES}

[1] K.J. Puttlitz, K.A. Stalter, Handbook of Lead-Free Solder Technology for Microelectronic Assemblies, New York: Marcel Dekker (2004).

[2] J. Bath, Lead-Free Soldering, New York: Springer (2007).

[3] J.H.L. Pang, Lead Free Solder, Mechanics and Reliability, New York: Springer (2012).

[4] T.K. Lee, T.R. Bieler, C.U. Kim, H. Ma, Fundamentals of Lead-Free Solder Interconnect Technology; From Microstructures to Reliability, New York: Springer (2015).

[5] A.Z. Miric, New developments in high-temperature, high-performance lead-free solder alloys. Proceedings of the SMTA International Conference, Orlando, FL, October 24-28. (2010).

[6] H. Steen, B. Toleno, Development of a lead-free alloy for high-reliability, high-temperature applications (2010)., http://www. hlinstruments.com/RoHS_articles (downloaded on 01/07/2016).

[7] http://elektro-net.hu/gyartosor/2075-sacx-valasz-az-uj-kihivasraaz-olommentes-forrasztas-teruleten (downloaded on 01/07/2016). 